\section{(1) \\ CrossMark}

\title{
Post-intubation subglottic stenosis: aetiology at the cellular and molecular level
}

\author{
Emma R Dorris (10 ${ }^{1,2}$, John Russell ${ }^{3}$ and Madeline Murphy ${ }^{1,2}$
}

Affiliations: ${ }^{1}$ National Children's Research Centre, Our Lady's Children's Hospital, Dublin, Ireland. ${ }^{2}$ School of Medicine, University College Dublin, Dublin, Ireland. ${ }^{3}$ Children's Hospital Ireland Crumlin, Dublin, Ireland.

Correspondence: Emma R Dorris. University College Dublin Conway Institute, Belfield, Dublin 04 V1W8, Ireland. E-mail: emma.dorrisQucd.ie.

@ERSpublications

COVID-19 may cause an increased incidence of subglottic stenosis (SGS). In this review, the cellular and molecular aetiology of post-intubation SGS is outlined and we discuss how better knowledge of the underlying biology can inform SGS management. https://bit.ly/2RSliRK

Cite this article as: Dorris ER, Russell J, Murphy M. Post-intubation subglottic stenosis: aetiology at the cellular and molecular level. Eur Respir Rev 2021; 30: 200218 [https://doi.org/10.1183/16000617.02182020].

ABSTRACT Subglottic stenosis (SGS) is a narrowing of the airway just below the vocal cords. This narrowing typically consists of fibrotic scar tissue, which may be due to a variety of diseases. This review focuses on post-intubation (PI) SGS. SGS can result in partial or complete narrowing of the airway. This narrowing is caused by fibrosis and can cause serious breathing difficulties. It can occur in both adults and children. The pathogenesis of post-intubation SGS is not well understood; however, it is considered to be the product of an abnormal healing process. This review discusses how intubation can change the local micro-environment, leading to dysregulated tissue repair. We discuss how mucosal inflammation, local hypoxia and biomechanical stress associated with intubation can promote excess tissue deposition that occurs during the pathological process of SGS.

\section{Introduction}

The subglottic space is the lowest part of the larynx, the area from the inferior margin of the vocal cords to the lower border of the cricoid cartilage. The cricoid cartilage is the only complete cartilaginous ring of the laryngeal skeleton [1]. The cricoid ring is composed of hyaline cartilage and covered by a fibrous perichondral membrane. The subglottic mucosa consists of pseudostratified ciliated columnar epithelial cells with a rich population of goblet cells, the basement membrane and lamina propria which is rich in fibroblasts and leukocytes [2]. Translaryngeal intubation may result in damage to the subglottis. Injury to the larynx is not uncommon and most injuries occur during initial placement. One prospective cohort study of 100 consecutive patients reported that $57 \%$ of patients had signs of acute laryngeal injury as evidenced by the presence of ulceration or granulation tissue [3]. The majority of laryngeal injuries will not cause clinically significant outcomes [4]. However, stenosis can occur as a late complication of intubation and can take weeks to months to develop after the initial intubation. PI-SGS is an important long-term outcome of intubation, the incidence of which ranges from $0.3 \%$ to $>11 \%[5,6]$.

\section{Risk factors}

Pathogenesis of PI-SGS remains unclear; however, several risk factors have been identified. Traumatic intubation, either due to mucosal injury or cuff pressure necrosis, is a well-established cause of PI-SGS [3, 7].

Provenance: Submitted article, peer reviewed

Received: 6 July 2020 | Accepted after revision: 20 Sept 2020

Copyright $\odot$ ERS 2021. This article is open access and distributed under the terms of the Creative Commons Attribution Non-Commercial Licence 4.0. 
Multiple intubations and unplanned extubations are also risk factors [8, 9]. In addition, multiple studies have demonstrated that the risk of PI-SGS increases with the duration of intubation. Length of intubation is frequently considered to be the most relevant risk factor for the development of PI-SGS in both adults and children [10-12]. Severe acute respiratory syndrome coronavirus 2 (SARS-CoV-2) and the associated COVID-19 pandemic has led to an unprecedented increase in critically ill patients requiring prolonged mechanical ventilation [13].

Pre-COVID-19, tracheostomy would be common practice in patients who require extended time on mechanical ventilation. However, SARS-CoV-2 is highly infective with a high rate of transmission. The procedure of tracheostomy is aerosol-generating, thus healthcare workers are at risk of SARS-CoV-2 infection both during the insertion procedure and subsequent care even when appropriate personal protective equipment (PPE) is used [14]. Recent guidelines for the conduct and management of tracheostomy during the COVID-19 pandemic urge caution, and recommend at least day 10 of mechanical ventilation prior to tracheostomy, and even then, it should only be considered when patients are showing signs of clinical improvement [14]. Hence, a surge in the incidence of PI-SGS is predicted in the post-COVID-19 patient population.

Infection, particularly respiratory infection within 14 days of intubation, is a risk factor for PI-SGS [15, 16]. Patient specific factors may also contribute to risk of developing PI-SGS. In adults, obesity and diabetes mellitus are associated with an increased risk of PI-SGS [17, 18]. Diabetes is also a risk factor for gastroesophageal reflux disease (GERD). GERD has been associated with SGS in both adults and children $[19,20]$. In children, SGS is most commonly associated with pre-term infants and/or low birth rate $[21,22]$.

\section{The normal wound-healing process}

PI-SGS is considered to be the result of a poorly controlled and excessive wound-healing response that leads to fibrotic scarring. The normal functional process of wound healing occurs through four distinct programmed phases: haemostasis, inflammation, proliferation and remodelling. These phases are synchronised, temporally controlled, overlap and involve a complex interplay between different cell types, cytokines, mediators and the vasculature [23]. Phases 1-3 typical last up to 3 weeks, with the remodelling phase lasting from weeks to years [24]. Deviation from the typical wound-healing sequence can lead to dysfunctional wound repair; with pathologic fibrotic response and chronic nonhealing wounds representing either end of the dysregulation spectrum.

\section{Haemostasis}

Haemostasis is the earliest phase of wound healing occurring immediately upon wounding. This phase is aimed at arresting bleeding from an injured blood vessel, typically via a platelet plug. Haemostasis is triggered by damage to the vascular endothelium, which reveals the sub-endothelial extracellular matrix (ECM) [25]. Exposure of matrix components facilitates platelet adhesion to ECM resulting in platelet activation and initiation of the haemostatic cascade [26]. Activated platelets contain abundant chemokines and cytokines at concentrations far greater than the plasma concentration [27]. This includes those involved in immune cell recruitment, including members of the tumour necrosis factor (TNF) superfamily, and growth factors such as transforming growth factor (TGF)- $\beta$ and fibroblast growth factor (FGF) [28, 29]. This upregulation of adhesion molecules, chemokines, cytokines, and growth factors at the wound site leads to phase 2 of wound healing: inflammation.

\section{Inflammation}

Inflammation is promoted at the wound site when tissue damage is sensed by tissue-resident macrophages via damage associated molecular patterns (DAMPs). Neutrophils kill and degrade potential pathogens and secrete cytokines and growth factors that recruit and activate more neutrophils, promote angiogenesis and stimulate proliferation of cells such as fibroblasts and epithelial cells [30, 31]. Monocyte-derived macrophages arrive at the wound site between 24-72 hours post-injury, with peak macrophage accumulation 4 to 7 days post-injury [24, 32].

Macrophages are phagocytic scavenger cells with a role in phagocytosing pathogens, cellular debris, neutrophils and other apoptotic cells [33]. Macrophages are an important source of chemokines, matrix metalloproteinases (MMPs), and other inflammatory mediators that drive the initial inflammatory response [34]. Macrophages can activate and recruit innate and adaptive immune cells, including T-cells [35].

As the initial danger from injury is contained, pro-inflammatory signalling molecules decrease. There is an increase in regulatory T-cells (Tregs), and increases in IL-10 and TGF- $\beta$, creating an anti-inflammatory micro-environment conducive for the predominant macrophage population to adopt a wound-healing phenotype that contributes to phase 3 of wound healing, the proliferation phase [36]. 


\section{Proliferation}

Typically, 4 days post-injury, as inflammation is in the resolution phase, the proliferation phase of wound healing starts [28]. The aim of this phase is to promote formation of a new epithelial barrier via granulation and re-epithelialisation [37]. Macrophages produce a variety of factors that stimulate the proliferation, differentiation and activation of fibroblasts, epithelial cells, endothelial cells, and stem and progenitor cells in the wound bed [38-40].

Fibroblasts are key cells during this phase, depositing ECM composed of fibronectin, proteoglycans, collagens and hyaluronic acid [41]. In the wound bed, migratory fibroblasts are differentiated into activated myofibroblasts. Myofibroblasts can extend pseudopodia and attach to the ECM components including fibronectin and collagen [42]. These myofibroblasts promote wound edge approximation by retracting the pseudopodia. This process of slow retractile contraction leads to wound closure [43].

Re-epithelialisation is required to provide an epithelial barrier for wound coverage. Granulation tissue forms a new scaffold for basal cell migration at later stages of the repair process [24]. An abnormal response of the other cells interacting with the epithelium such as fibroblasts and macrophages, can severely affect the dynamic progression of repair and regeneration [44].

\section{Remodelling}

The remodelling phase of wound healing can last from months to years. The goal of this phase is to remodel the ECM to that of normal tissue. The highly cellular granulation tissue has its network of blood vessels pruned, and most fibroblasts, immune cells and endothelial cells undergo apoptosis [45, 46]. Metalloproteinases (MMPs) are necessary to organise and align the temporary granulation ECM into the mature permanent ECM structure. The wound undergoes physical contraction throughout the entire process. The relative balance of metalloproteinases, including MMPs and ADAMs (A disintegrin and metalloproteases), and their inhibitors is critical at this stage [47].

TGF- $\beta$ signalling and mechanical stress are both key regulators of this phase $[48,49]$. The current model suggests that biomechanical and chemical cross talk is necessary for fine tuning remodelling and appropriate scar maturation [50]. Biomechanical stretch alone can only promote a limited contractile response, whereas the addition of TGF- $\beta 1$ promotes the formation of fibrotic tissue [51].

Increasing evidence suggests that the remodelling phase of wound healing may be insufficient in SGS [52]. The resulting imbalance between the synthesis and degradation of the ECM can result in excess accumulation of matrix components within the wound and reduced degradation. Thus, an altered and inappropriate matrix, rather than simply too much ECM, is likely to underpin SGS.

\section{Molecular mechanisms and key mediators of abnormal wound healing in PI-SGS Fibrosis}

Fibrosis is an excessive deposition of the ECM that can affect virtually every organ system, including the airway. The excess ECM often disrupts the physiological architecture of the organ and can lead to organ malfunction. When this disruption leads to abnormal narrowing of a passageway, it is called fibrotic stenosis. This aids in distinguishing the underlying pathology between PI-SGS and inflammatory SGS, such as that observed in some forms of granulomatosis [53]. In fibrosis, tissue remodelling does not terminate in a controlled manner, rather it persists as a chronic uncontrolled process. During this process, myofibroblast apoptosis is dysregulated and fibroblast activation persists [54]. The progressive deposition of ECM increases tissue stiffness. This can lead to hypoxia and self-amplifying feedback loops of fibroblast activation and tissue remodelling [55]. The pathology of fibrosis is not well understood, but genetic susceptibility, epigenetic modification, aberrant activation of the inflammatory response, perturbations in the cellular immune response, altered metabolism and aberrant activation of latent TGF- $\beta$ have all been associated with the development of fibrosis [56-62]. PI-SGS can be described as a fibrotic stenosis that recapitulates the components of scarring and fibrosis [63]. By examining the associated risk factors of PI-SGS and their potential contributions to the development of fibrosis, we may gain further insight into the underlying pathobiology of PI-SGS.

\section{TGF- $\beta$}

The TGF- $\beta$ superfamily have critical roles in a diverse range of cellular responses, including development, homeostatic and physiological responses. TGF- $\beta$ is the master regulator driving fibrosis in multiple organ and tissue types. TGF- $\beta$ is ubiquitously expressed and plays an active role in the immune and wound-healing responses and is critical for tissue homeostasis. However, if TGF- $\beta$ signalling is dysregulated and amplified it can result in upregulation of profibrotic TGF- $\beta$-regulated genes including growth factors, ECM proteins, adhesion proteins and members of the TGF- $\beta$ signalling family. 
TGF can signal through multiple pathways. Signalling downstream of TGF and bone morphogenetic protein (BMPs) (figure 1) are frequently described as distinct downstream pathways, although cross talk of pathways does occur [64]. The response to any given dose of TGF- $\beta$ occurs in a cell-specific manner, determined by the levels of signalling proteins produced by that cell. The SMAD family proteins are the major mediators of TGF- $\beta$-induced transcriptional responses. However, pathway activation can occur via non-SMAD kinase cascades (noncanonical signalling). Noncanonical signalling can result in diverse downstream effects including gene expression, actin cytoskeleton and the microtubule network reorganisation, regulation of tight junctions and protein synthesis [65]. Thus, it is not just the dose of TGF ligand that determines the tissue response to TGF, but the levels of signalling proteins and interaction of signalling pathways that determines the sensitivity and response of individual cells to TGF- $\beta$. The complexity of TGF- $\beta$ signalling is such that the mechanism of TGF- $\beta$ signalling in fibrotic diseases are still not fully understood.

\section{Fibroblasts and myofibroblasts}

The key effector cells of fibrosis are activated myofibroblasts. TGF- $\beta$ plays numerous roles in the differentiation and activation of myofibroblasts. Epithelial to mesenchymal transition (EMT) is the process whereby mature epithelial cells undergo phenotypic transition into fully differentiated mesenchymal cells of either fibroblast or myofibroblast phenotype. EMT is frequently observed in response to epithelial stress or injury in adult tissues. TGF- $\beta$ plays an important role in EMT through effects involving both canonical and noncanonical signalling [66].

During EMT, the transcription profile is switched such that epithelial cells lose their original shape, cellcell contact and epithelial cell-specific protein expression. TGF- $\beta$ signalling, typically via SMAD-mediated pathways, results in inhibition of these epithelial genes through activation and induction of a variety of transcription factors and subsequent binding to SMAD-binding elements (SBE). It can also activate TGF- $\beta$-induced mesenchymal target genes including collagen, plasminogen activator inhibitor-1, connective tissue growth factor, FGF and $\alpha$-smooth muscle actin ( $\alpha$-SMA), which are necessary for the cell to gain the typical features of mesenchymal cells. Noncanonical TGF- $\beta$ signalling is required for the morphological changes of the cells, including dissolution of tight junctions and cytoskeleton rearrangements. Activation of noncanonical TGF- $\beta$ pathways is also important for cross talk with other co-operative EMT pathways, such as the Wnt family pathway [67].

TGF- $\beta$ mediates fibroblast differentiation into myofibroblasts. Myofibroblasts express high levels of fibrogenic cytokines. They invade and repair injured tissues by secreting and organising the ECM and by developing contractile forces. Typically, myofibroblasts undergo apoptosis at the end of the repair response. However, in pathological situations, myofibroblasts can remain, leading to excessive scarring and fibrosis. Evasion of apoptosis and/or persistent differentiation of myofibroblasts creates a profibrotic cascade and prevents the resolution of fibrosis [68]. TGF- $\beta$ induces the production of $\alpha$-SMA, a contractile protein whose expression is a hallmark of myofibroblasts. TGF- $\beta 1$ also promotes the induction, expression and deposition of large amounts of ECM, particularly fibrillar collagens and fibronectin. It also upregulates tissue inhibitors of metalloproteinases (TIMP) leading to reduced MMP activity. Thus, TGF- $\beta$ is important for the induction of fibrosis; however, its multifunctional and context-specific roles make the relative contributions of TGF- $\beta$ pathways and signalling mechanisms difficult to fully elucidate.

\section{Intubation and abnormal healing in subglottic stenosis \\ Mucosal trauma}

One of the major risk factors of SGS is mucosal injury. Direct injury to the subglottis as a result of intubation is quite common; however, this is typically transient $[69,70]$. The risk of injury increases when intubation is performed in the intensive care unit (ICU), although risk can be somewhat mitigated when performed by expert laryngoscopists within the same setting [71]. Most cases of subglottic damage are reported to be caused by movement of the endotracheal tube causing abrasion of the mucosa, and pressure necrosis of the posterior mucosa by the endotracheal tube. Due to the anatomy of the larynx, the subglottis is a common site of intubation-related injury (figure 2). Progression of mucosal injury to stenosis is rare, but depth of injury has been implicated in the progression to PI-SGS [72].

Multiple animal models have demonstrated that injury depth is an important factor for the development of SGS $[73,74]$. In vivo studies have demonstrated that injuries to the mucosa and submucosa typically result in normal healing, whereas injuries that reach the underlying lamina propria, perichondrium or cartilage are more likely to advance to stenosis $[72,75,76]$. Deeper trauma activates fibroblasts of the lamina propria. These fibroblasts typically play a vital role as the resident mesenchymal cells beneath the epithelium. They coordinate much of the communication between epithelial and inflammatory cells and play a critical homeostatic role upon injury [77]. Lamina propria fibroblasts can demonstrate a spatial 


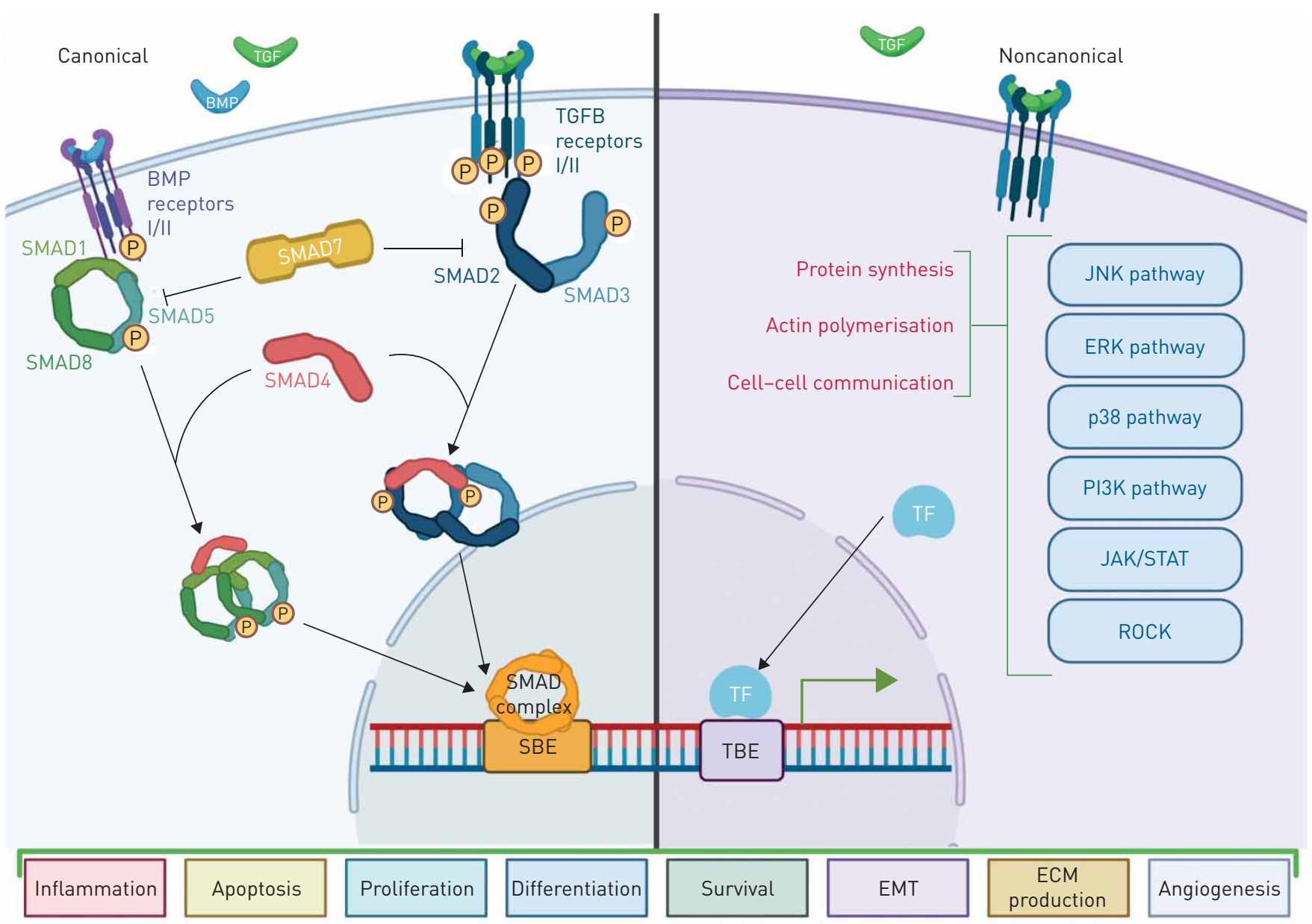

FIGURE 1 TGF- $\beta$ signalling pathways. TGF- $\beta$ is a central mediator of fibrosis. Canonical signalling via SMAD family proteins can initiate downstream gene expression or repression. Noncanonical signalling can occur via a number of pathways, which can lead to a diverse array of outcomes dependent upon context. A cell's phenotypic response to TGF ligands is dependent on the balance of signalling proteins and pathway interactions. SBE: SMAD-binding element; TBE: transcription factor binding element; TF: transcription factor; P: Phosphorylation; TGF: transforming growth factor; BMP: bone morphogenetic proteins; JNK: c-Jun N-terminal kinase; ERK: extracellular-signal-regulated kinase; p38: p38 mitogen-activated protein kinase; PI3K: phosphoinositide 3-kinase; JAK/STAT: Jak family tyrosine kinases/signal transducer and activator of transcription; ROCK: Rho-associated protein kinase. Figure was created with BioRender.com.

relationship, and disturbance of fibroblast: fibroblast interactions, as occurs during deep tissue injury, are involved in regulation of inflammatory cell recruitment and activation [78]. Thickening of the lamina propria has been associated with PI-SGS [79].

The resident lamina propria fibroblasts produce large quantities of collagen and inflammatory cytokines, including TGF- $\beta$. In the bronchial airway, it has been demonstrated that they synthesise less collagenase, thereby decreasing collagen degradation [80]. However, it has yet to be determined if this is the same for the laryngeal airway.

The subglottis is the narrowest region of the upper airway and prolonged intubation can induce prolonged inflammation and prolonged contact with a rigid cannula can add the force of mechanical stiffness on the local tissue [81]. In experimental models of mucosal fibrosis, stiffness led to increased proliferation, decreased MMP expression and enhanced myofibroblast differentiation resulting in the adoption of a profibrotic phenotype by fibroblasts [82]. In addition, chronic inflammation has been associated with dysregulated tissue remodelling and profibrotic responses in multiple mucosal tissues [83].

A key mediator of chronic inflammation-induced fibrosis are macrophages, which can be recruited and activated by fibroblasts of the lamina propria [34]. Damage of the lamina propria can produce ECM fragments, which have been shown to be important drivers of fibrosis by stimulating chemokine and pro-inflammatory cytokine production by macrophages [84]. Although inflammatory macrophages are crucial for the initial stages of wound healing, prolonged presence of inflammatory macrophages delays the resolution of the inflammation and can exacerbate the tissue-damaging inflammatory response leading to 

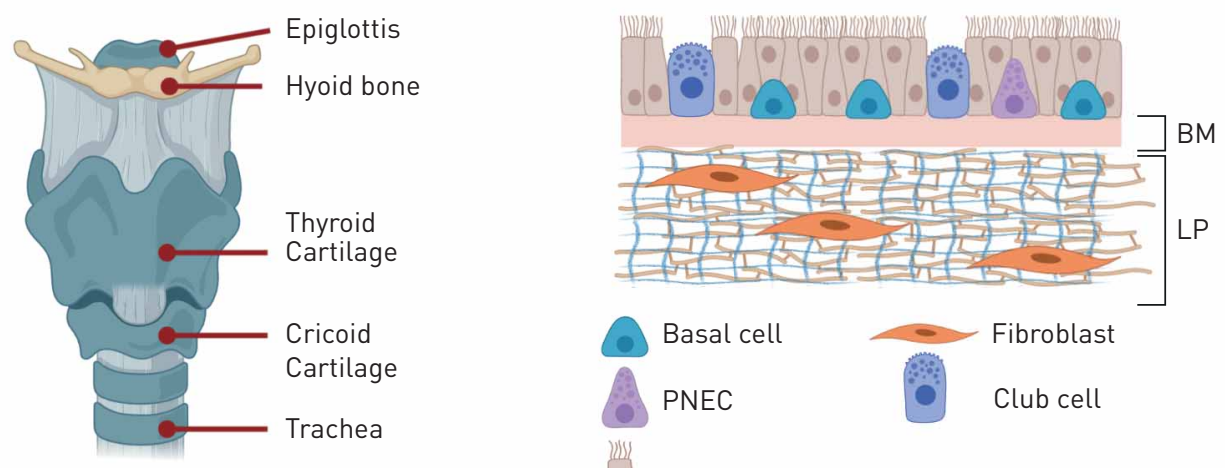

Pseudostratified columnar epithelial cell
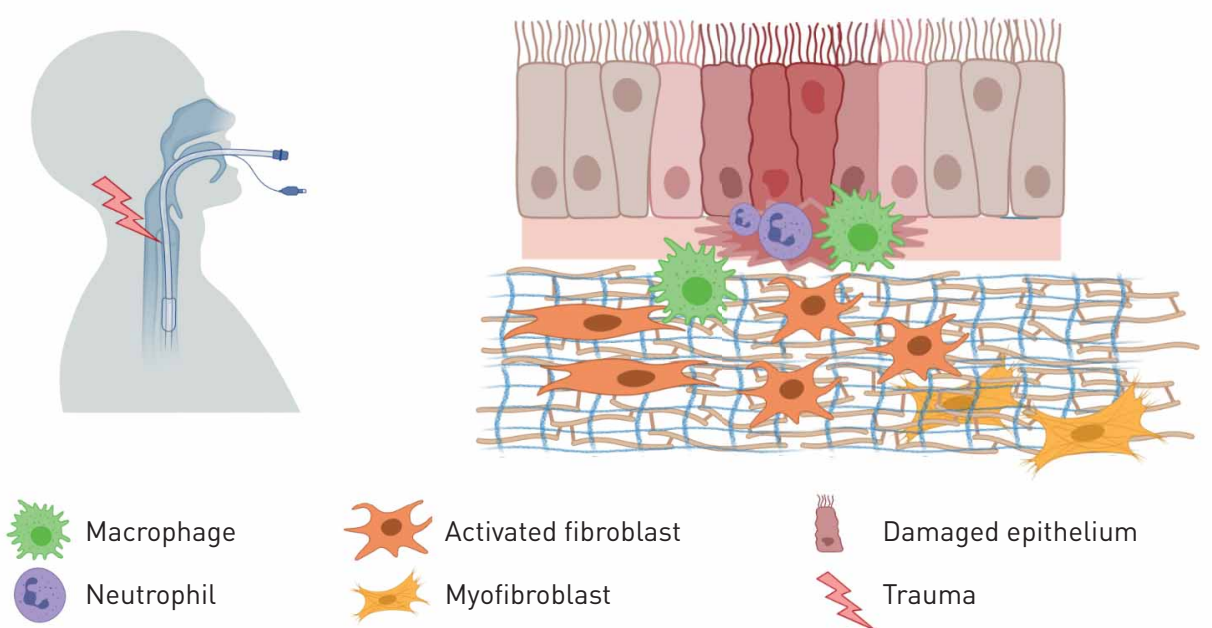

Activated fibroblast

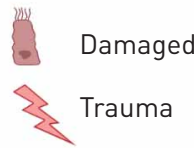

Myofibroblast

FIGURE 2 The anatomy of the larynx and tracheal mucosa. Top: Anatomy of the larynx and normal pseudostratified columnar epithelium of the airway. Bottom: Intubation can cause mucosal trauma resulting in leukocyte recruitment, activation of fibroblasts and transdifferentiation to myofibroblasts. BM: basement membrane; LP: lamina propria; PNEC: Pulmonary neuroendocrine cells. Figure was created with BioRender. com.

fibrotic scarring [85]. Key among the pro-inflammatory cytokines produced by these cells are TNF, IL-1 $\beta$ and IL6, all of which have been observed to be increased in SGS [86, 87].

TNF and IL1 $\beta$ can activate myofibroblasts and lead to misbalanced MMP/TIMP expression which may be important in orchestrating fibrotic pathogenesis [88]. This is coupled with the observation from intestinal fibrosis that TNF has an additive effect on progression to fibrosis by also promoting collagen accumulation and myofibroblast proliferation [89]. TNF promotes IL6, a pleiotropic cytokine implicated in the development of pathologic hypertrophy and fibrosis in chronic cardiac interstitial fibrosis, at least in part via augmentation of TGF- $\beta$ signalling [90].

\section{Ischaemia}

Subglottic ischaemia is a recognised common complication of intubation, with the risk increasing with duration of intubation [91]. The narrow anatomy of the subglottis results in it being a common region of local mucosal ischaemia. The laryngeal and tracheal blood supply is segmental and compression can cause regional ischaemia of the cartilaginous rings [92]. Ischaemia can lead to mucosal necrosis, resulting in the loss of regional mucosa and structural integrity of the airway wall. This can also make the region more susceptible to infection. Progression to necrosis is associated with longer intubation duration. Ischaemia leads to tissue hypoxia, if the hypoxic state is prolonged, cellular death may occur via necrosis.

Ischaemia leads to hypoxic cellular injury that occurs because of energetic/metabolic failure. The lack of oxygen blocks the mitochondrial respiration and anaerobic metabolism becomes the major energy source. As this progresses, glucose, glycolysis and pentose phosphate are depleted leading to oxygen-glucose 
deprivation, which can completely deplete the cellular NAD+ and ATP pools [93]. This causes severe metabolic suppression [94, 95]. In addition, impaired mitochondrial respiration can increase membrane permeability of the mitochondria [96, 97]. Together, this ultimately results in necrotic cell death. Considering the local inflammatory environment, necroptosis is also likely to play a role, but this has yet to be investigated in PI-SGS [98].

In response to necrosis, mitosis and cellular regeneration are initiated. Resting stem cells can be differentiated into myofibroblast-like cells that can synthesise ECM proteins. Excessive synthesis or activation of these cells can lead to deposition of mature collagen fibrils in the ECM and results in fibrosis (figure 3). Ischaemia with confluent necrosis can amplify the process of regeneration, increasing the risk of fibrosis [99].

Hypoxia is a recognised regulator of tissue repair and a driving factor in many fibrotic diseases [100, 101]. This is not only due to the pivotal role of hypoxia in inflammation, reviewed in [102], but also due to its direct effect on fibroblasts. Hypoxia, typically via the hypoxia inducible factor 1 subunit alpha (HIF1A) pathway, can promote fibrosis on multiple levels. In fibroblasts, HIF1A can target pyruvate dehydrogenase kinase in the mitochondria to switch metabolism of the cells to glycolysis, leading to myofibroblast differentiation [103]. HIF1A stabilisation, as occurs in ischaemia, can promote collagen deposition and chemotaxis [104]. Furthermore, hypoxia can stimulate the upregulation of a panel of profibrotic genes including platelet derived growth factors (PDGFs), FGFs, fibronectin and connective tissue growth factors, and members of the TGF- $\beta$ pathway [105-109].

\section{Biomechanical stress}

Intubation and mechanical ventilation are reliant upon repeated applications of force and pressures. In addition, the rigidity and size of the tube can load additional biomechanical force on the tissue. Indeed,

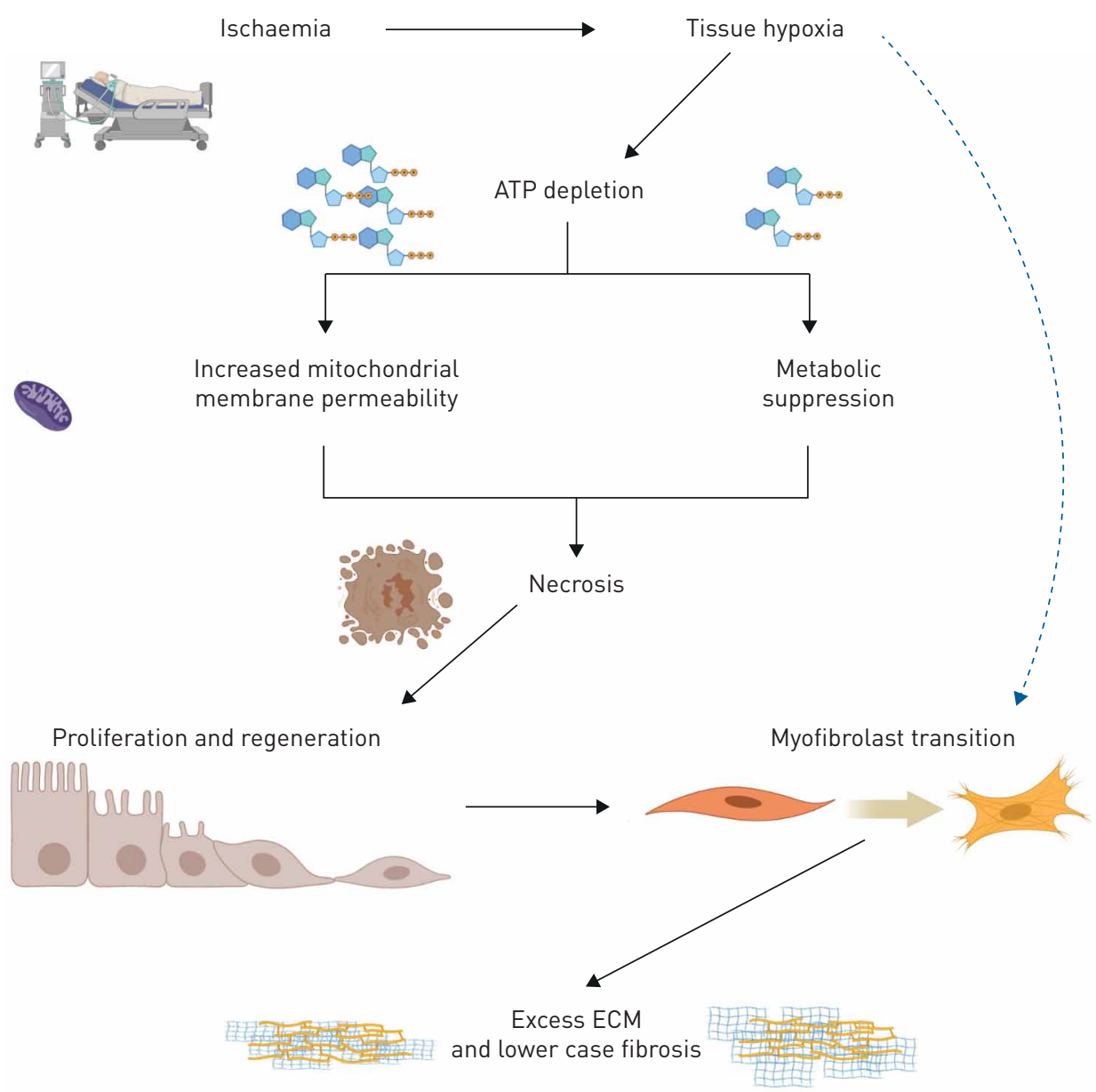

FIGURE 3 Prolonged intubation can cause ischaemia and tissue hypoxia leading to fibrosis. ECM: extracellular matrix. Figure was created with BioRender.com. 
excessive cuff pressure and oversized tubes are risk factors for PI-SGS [110, 111]. Part of this risk is due to the mucosal injury that can occur from cuff contact with the trachea; however, biomechanical stress can also affect the local micro-environment via mechanosensory signalling.

The epithelium of the airway tract mucosa contributes significantly to the barrier function of airway tract [112]. Mechanoregulation of barrier function includes cellular responses to stretch and shear, via activation of epithelial and endothelial cells and fibroblast response to the rigidity and stretch of the ECM [113]. Furthermore, a phenomenon whereby gradients of mechanical properties within a tissue facilitate long-range migration of cells has been implicated in the development of fibrosis. This increased infiltration of cells is cell-cell- and cell-matrix-mediated and contributes to the early changes in tissue stiffness observed prior to the de novo deposition of ECM [114]. In cell-cell signalling, physical tension plays an

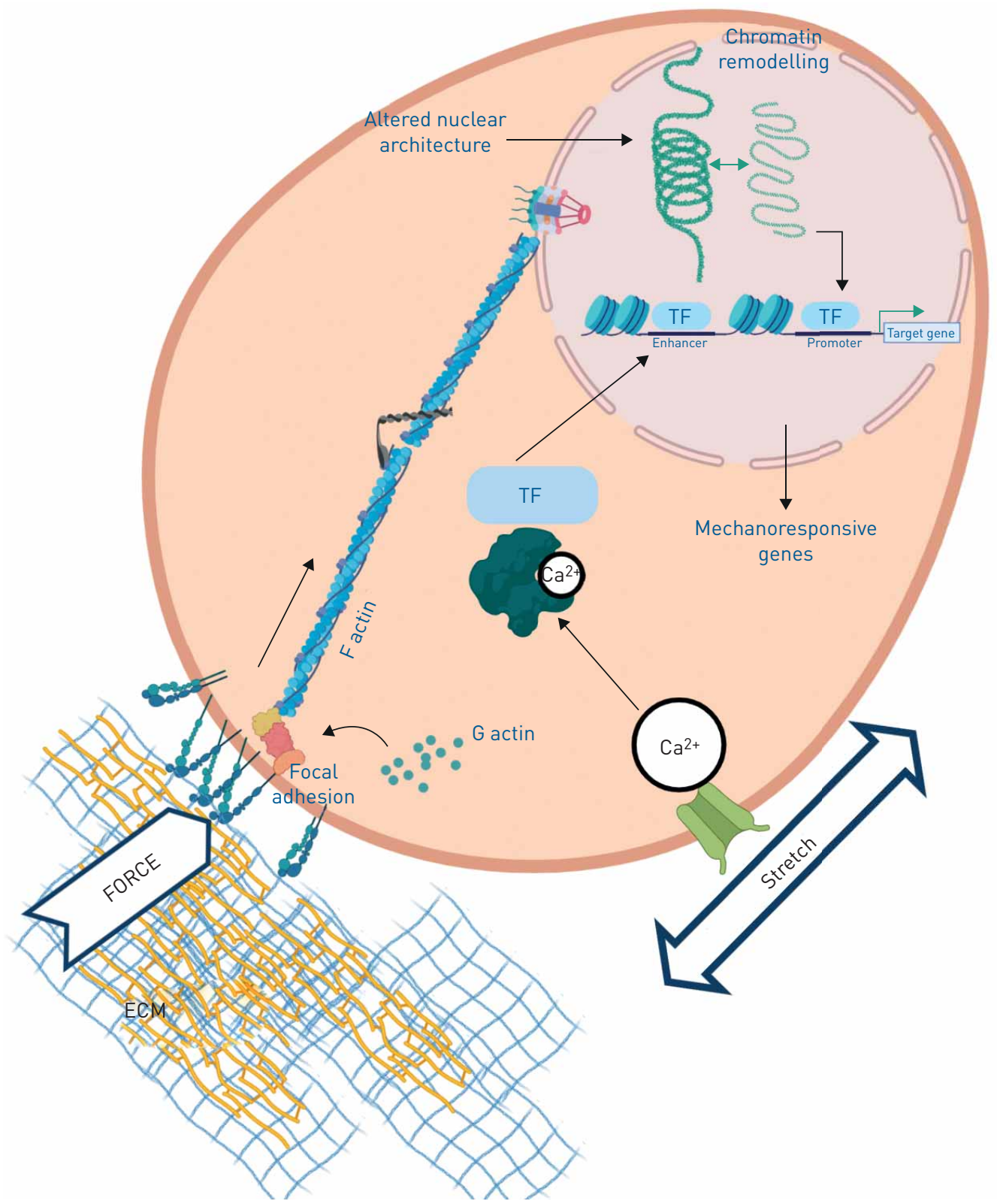

FIGURE 4 Biomechanical stress can induce mechanosignalling and contribute to dysregulated wound repair. External forces such as compression or spatial restraints act through focal adhesions. Free (G) actin undergoes actin polymerisation. Actomyosin contraction leads to changes in nuclear architecture and chromatin remodelling, allowing activation of mechanoresponsive genes. Mechanical stretch forces activate stretch-activated ion channels, leading to the activation and translocation of transcription factors resulting in activation of mechanoresponsive genes. TF: transcription factor; $\mathrm{Ca}^{2+}$ : Calcium ions; ECM: extracellular matrix: $f$ actin: fibrous actin; $G$ actin: globular actin. Figure was created with biorender.com. 
important role in downstream signalling via cell-cell adhesion complexes. Furthermore, cell-cell junctions themselves regulate cell polarity, cell state, migration and barrier function contributing to long-range tissue integrity and morphogenesis [115]. Both externally generated physical forces and internally generated cytoskeletal forces can disrupt cell-cell adhesion contributing to fibrosis [116].

Fibroblast plasticity and adaption to the changing mechanical micro-environment of tissue undergoing remodelling is an important part of normal tissue repair. In normal repair, decreasing stresses in the wound bed induces activated myofibroblasts to return to a more quiescent state or undergo apoptosis [117]. Exposure to chronic mechanical stresses can maintains myofibroblast activation. It also stimulates fibroblast ECM production resulting in matrix stiffening, which combined promotes a nonhomeostatic feedback loop that amplifies matrix deposition in a cell-autonomous fashion and promotes fibrosis [118, 119]. An addition pivotal factor in the role of biomechanical force is that TGF- $\beta$ is regulated by myofibroblast contractile forces and tissue stiffness, thus persistent biomechanical signalling can lead to defective TGF- $\beta$ signalling and enhance the fibrotic cascade $[120,121]$ (figure 4).

\section{Using biological innovations to inform PI-SGS management}

Advances in intubation with the use of video-laryngoscopes reduce excessive, repeated intubations and trauma to the subglottis. The development of an improved range of endotracheal tubes with low pressure cuffs has also helped greatly. In children the use of the microcuff tube with a distal low pressure cuff has reduced the incidence of subglottic trauma and stenosis, as discussed in depth in [122]. Early tracheostomy in adult intensive care units thus avoiding prolonged intubation, pressure monitoring and better training have all contributed to reducing the incidence of PI-SGS [123].

In the COVID-19 era, however, particularly in COVID-positive patients, there is a reluctance to proceed to early tracheostomy and prolonged intubation in adult ICUs has become commonplace thus increasing the risk of severe PI-SGS. Tracheostomy has wide ranging impacts on the quality of life of both the patient and their caregivers [124].

Prior to proceeding to tracheostomy for PI-SGS, endoscopic management is often tried first in an attempt to avoid open surgery or tracheostomy particularly if the stenosis is less severe and less extensive. This can include serial balloon dilations, radial incisions with carbon dioxide laser or cold steel, and combinations of the above. Adjunctive measures include glucocorticoid injections and topical mitomycin-c.

Corticosteroids can prevent the development of severe PI-SGS as they are antifibrotic and anti-inflammatory. The mechanism of action of intralesional steroid injection is not completely understood. Steroids are known to decrease collagen synthesis and fibrosis. The glucocorticoid triamcinalone decreases the synthesis of a collagenase inhibitor alpha 2 macroglobulin. It is also thought that triamcinolone prevents the cross-linking of collagen that results in scar contracture. Thus, when the scar is stretched, for a balloon dilation for example, and corticosteroid is injected into it the contracture will not occur.

Topical mitomycin-C (MMC) application has been widely used in the past immediately post-dilation, aimed at preventing re-stensosis. MMC is an antineoplastic antibiotic that has been used off-label in the treatment of hypertrophic and keloids scars in addition to SGS. MMC acts as an anti-proliferative agent and functions via cross-linking DNA. MMC is an alkylating agent that can inhibit both DNA synthesis and protein synthesis. It can induce fibroblast apoptosis, including human vocal-chord derived fibroblasts $[125,126]$. Although prior studies have generally favoured the use of MMC, debate continues over its proper role and safety profile [127]. Clinical trial evidence of the benefit of MMC in the management of PI-SGS has largely demonstrated minimal or no benefit, and currently the most widely used adjuvant agent is intralesional corticosteroid injection [128-130].

The profibrotic actions of TGF- $\beta$ have long made it a target of interest in the prevention of fibrosis, and fibrosis-related diseases such as SGS. Anti-TGF- $\beta$ therapies have been trialled in experimental models of SGS with limited success. In a rabbit model of SGS, treatment with a TGF- $\beta$-inhibitor peptide p17 significantly reduced the fibrotic thickness and density of myofibroblasts in stenotic lesions, but failed to improve the luminal area [131]. In a canine model of experimental SGS, treatment with an anti-TGF- $\beta$ antibody induced a statistically significant, albeit small, improvement in percentage of tracheal stenosis compared with saline control [132]. Although anti-TGF- $\beta$ therapies promise to have a major impact in theory, the evidence to date has demonstrated significant concerns regarding efficacy, safety and off-target effects. Numerous TGF- $\beta$ pathway targeted therapies are in pre-clinical or clinical trial for a variety of diseases, including cancer, diabetic neuropathy, systemic sclerosis and fibrosis. An unfortunate common theme among these trials is early termination due to safety concerns [133]. TGF- $\beta$ has a wide range of pleiotropic biological activities and contributes to many physiological processes, in addition to pathological 
processes. Thus, targeting of TGF- $\beta$ significant potential risks. Targeting downstream of TGF- $\beta$, or targeting the local micro-environment that facilitates fibrosis, may be a more promising tactic.

A number of antifibrotic medications are currently approved for clinical use. Pirfenidone is a pyridone derivative that has antifibrotic and anti-inflammatory effects available for the treatment of idiopathic pulmonary fibrosis (IPF). Pre-clinical research in mouse and rat models of tracheal stenosis indicate pirfenidone may have benefit in preventing fibrosis and luminal narrowing. Its target and mechanism of action are unknown, but it has well-established antifibrotic properties in animal models of fibrosis including reduction of fibroblast proliferation and inhibition of collagen production [134]. Also approved for IPF is the antifibrotic and small molecule kinase inhibitor nintedanib. Nintedanib acts by binding the intracellular ATP binding pocket of some growth factor receptors, thereby inhibiting autophosphorylation of those receptors and preventing downstream signalling cascades. Nintedanib inhibition results in reduced proliferation, migration and survival of fibroblasts [135]. Although nintedanib is a known EMT-suppressor and anti-fibrotic, it has yet to be tested in SGS.

Lanifibranor is an indole sulfonamide derivative that acts as a pan peroxisome proliferator-activated receptor (PPAR) agonist. PPAR are a family of ligand-activated nuclear hormone receptors. Lanifibranor acts as an agonist for all three PPAR isoforms and is currently under investigation for nonalcoholic steatohepatitis, a fibrotic disease of the liver. Lanifibranor recently met twin endpoints in the phase $2 \mathrm{~b}$ NATIVES trial, including significant improvement of fibrosis by at least one stage and it is currently awaiting regulatory decision. The precise mechanism of action is not fully known but the main antifibrotic activity of PPAR agonists is via suppression of TGF- $\beta$ signalling resulting in inhibition of fibroblast proliferation, induction of cell cycle arrest and apoptosis of myofibroblasts, prevention of fibroblast to myofibroblast differentiation and inhibition of collagen secretion [136]. PPAR agonists have yet to be tested clinically in SGS. However, given the key role of PPARs in airway inflammation, regulating tissue repair, and inhibiting TGF- $\beta$-induced EMT, investigation into the potential use of PPAR agonists in preventing PI-SGS is warranted.

Programmed cell death one (PD-1) is a cell surface membrane protein of the immunoglobulin superfamily. CD274, also known as PD-L1, is a ligand that binds with the receptor PD-1. PD-1/PD-L1 interaction plays a critical role in induction and maintenance of immune tolerance to self. The PD-1/ PD-L1 axis has diverse biological functions depending on the cellular context. Both PD-1 and PD-L1 can be increased in pulmonary fibrosis, with expression increased in T-cells and fibroblasts [137, 138]. Furthermore, PD-1 and PD-L1 are upregulated in post-intubation iatrogenic laryngotracheal stenosis compared with controls [139]. Ex-vivo, PD-1 pathway blockade can reduce TGF- $\beta$ secretion, and conversely, treatment with TGF- $\beta$ can increases PD-L1 expression on fibroblasts $[137,139]$. Thus, PD-1/ PD-L1 inhibitors may have potential for the treatment of fibrosis-related diseases. Current evidence indicates that the potential of PD-1/PD-L1 inhibitors does not expand to all checkpoint inhibitors [140], and that at least part of the function of the PD-1/PD-L1 axis in fibroblasts is independent of its well characterised immune-regulatory function [138].

A plethora of anti-TGF- $\beta$ drugs have been tested in pre-clinical models with positive results. However, to date, clinical translation has been poor. The reasons underlying the failure of translation are varied. However, the multifunctional role of TGF- $\beta$ and its key roles in tissue homeostasis makes targeting it exquisitely complex with adverse risks. Targeting TGF- $\beta$, although being investigated for treating cancer, has been shown to activate dormant tumours and cause progression of early-stage tumours. Pre-clinical studies have demonstrated that suppression of TGF- $\beta$ can reduce immunotolerance and stimulate the development of autoimmune diseases. The relationship between TGF- $\beta$ and cardiovascular disease is also complex. The PIROUETTE clinical trial is investigating pirfenidone for myocardial fibrosis, yet targeting of TGF- $\beta$ signalling in cancer trials has been associated with cardiovascular toxic side effects [141]. Thus, although anti-TGFs demonstrate great promise, better understanding of TGF biology, TGF plasticity and development of targeted delivery systems will be required to successfully recapitulate pre-clinical data in the clinic.

The initiation event for PI-SGS is known (intubation), which provides an opportunity for preventive interventions. Progress in the field of biomaterials may provide mechanisms to minimise risk by embedding antifibrotic or anti-inflammatory drugs within intubation tubes or cuffs [142]. As bioengineering increases, so too does the challenge of the inflammatory and fibrotic responses that implanted biomaterials elicit [143]. A range of anti-inflammatory polymeric coatings have already been developed to deliver therapeutics locally in a controlled, site-specific manner [144]. These include steroids, heparin and alpha-melanocyte-stimulating hormone $(\alpha-\mathrm{MSH})$, which has been tested in tracheal prostheses $[145,146]$. This developing field of smart and stimulation-responsive biomaterials offers great potential for novel prophylactic mechanisms for PI-SGS [147]. 
Drug-eluting stents are a potential, yet understudied, method for local administration of therapeutics to the trachea. Drug-eluting stents can deliver drugs directly to the diseased area, potentially avoiding systemic side effects. A recent pre-clinical investigation of rapamycin-eluting stent in a bleomycin-induced laryngotracheal stenosis mouse model demonstrated the feasibility of this method to reduce stenosis [148]. Rapamycin is a macrocyclic antibiotic and inhibitor of the mammalian target of rapamycin (mTOR). mTOR regulates cell cycle progression and ECM production in fibroblasts and has been studied as an antifibrotic in a range of organs. However, systemic side effects of oral rapamycin has hindered its progression to clinical use for treating fibrosis; although a small, short term clinical trial of rapamycin for IPF reported a decreasing number of circulating fibrocytes [149]. In vitro, rapamycin can inhibit proliferation, metabolism, and collagen deposition of human laryngotracheal stenosis-derived fibroblasts [150]. Thus, the pre-clinical research of rapamycin-eluting stent is compelling, not just for the proof-of-concept of a biocompatible stent for the airway, albeit in mice, but also for the efficacy of the locally delivered rapamycin at reducing fibrosis.

\section{Conclusions}

PI-SGS is a serious complication of intubation and its pathogenesis has yet to be fully elucidated. PI-SGS is a fibrotic condition, assumed to have a similar pathogenesis to hypertrophic or keloid scaring. The fibrotic response is complex, and prolonged intubation can create a macro- and micro-environment that fosters fibrosis. The current curative treatment of choice for severe laryngeal stenosis is laryngotracheal reconstruction or resection and both have high success rates in the long term. However, these children and adults often require multiple surgeries over a number of years before the tracheostomy is removed which is associated with negative psychosocial impacts and reduced quality of life. Development of nonsurgical interventions may help improve patient satisfaction and reduce psychosocial distress. Better understanding the pathobiology and elucidation of the molecular mechanisms of PI-SGS will facilitate novel preventive and therapeutic strategies to be developed, ultimately improving the lives of people with PI-SGS.

Acknowledgements: All images were created with BioRender.com

Conflict of interest: None declared.

Support statement: E.R. Dorris, J. Russell and M. Murphy are funded by the National Children's Research Centre supported by the Children's Medical and Research Foundation Crumlin (C/19/4). Funding information for this article has been deposited with the Crossref Funder Registry.

\section{References}

1 Scrase I, Woollard M. Needle vs surgical cricothyroidotomy: a short cut to effective ventilation. Anaesthesia 2006; 61: 962-974.

2 Stiblar-Martincic D. Histology of laryngeal mucosa. Acta Otolaryngol Suppl 1997; 527: $138-141$.

3 Shinn JR, Kimura KS, Campbell BR, et al. Incidence and outcomes of acute laryngeal injury after prolonged mechanical ventilation. Crit Care Med 2019; 47: 1699-1706.

4 Colton House J, Noordzij JP, Murgia B, et al. Laryngeal injury from prolonged intubation: A prospective analysis of contributing factors. Laryngoscope 2011; 121: 596-600.

$5 \quad$ Shah A, Carlisle JB. Cuffed tracheal tubes: guilty now proven innocent. Anaesthesia 2019; 74: 1186-1190.

6 Schweiger C, Marostica PJ, Smith MM, et al. Incidence of post-intubation subglottic stenosis in children: prospective study. J Laryngol Otol 2013; 127: 399-403.

7 Hom DB, Sun GH, Elluru RG. A contemporary review of wound healing in otolaryngology: current state and future promise. Laryngoscope 2009; 119: 2099-2110.

8 Thomas RE, Rao SC, Minutillo C, et al. Severe acquired subglottic stenosis in neonatal intensive care graduates: a case-control study. Arch Dis Child Fetal Neonatal Ed 2018; 103: F349.

9 Brown MS. Prevention of accidental extubation in newborns. Am J Dis Child 1988; 142: 1240-1243.

10 Cakir E, Atabek AA, Calim OF, et al. Post-intubation subglottic stenosis in children: Analysis of clinical features and risk factors. Pediatr Int 2020; 62: 386-389.

11 Rodríguez H, Cuestas G, Botto H, et al. Post-intubation subglottic stenosis in children. Diagnosis, treatment and prevention of moderate and severe stenosis. Acta Otorrinolaringol Esp 2013; 64: 339-344.

12 Manica D, Schweiger C, Maróstica PJ, et al. Association between length of intubation and subglottic stenosis in children. Laryngoscope 2013; 123: 1049-1054.

13 Meng L, Qiu H, Wan L, et al. Intubation and ventilation amid the COVID-19 outbreak: Wuhan's experience. Anesthesiology 2020; 132: 1317-1332.

14 McGrath BA, Brenner MJ, Warrillow SJ, et al. Tracheostomy in the COVID-19 era: global and multidisciplinary guidance. Lancet Respir Med 2020; 8: 717-725.

15 Suzumura H, Nitta A, Tanaka G, et al. Role of infection in the development of acquired subglottic stenosis in neonates with prolonged intubation. Pediatr Int 2000; 42: 508-513.

16 Yamada Y, Sugai M, Woo M, et al. Acquired subglottic stenosis caused by methicillin resistant Staphylococcus aureus that produce epidermal cell differentiation inhibitor. Arch Dis Child Fetal Neonatal Ed 2001; 84: F38-F39.

17 Nicolli E, Carey R, Farquhar D, et al. Risk factors for adult acquired subglottic stenosis. J Laryngol Otol 2017; 131: 264-267.

18 Ettema SL, Loerhl TA, Toohill RJ, et al. The prevalence of diabetes in a series of patients with subglottic stenosis. Ear Nose Throat J 2007; 86: 687-690. 

investigation of 225 patients using ambulatory 24-hour $\mathrm{pH}$ monitoring and an experimental investigation of the role of acid and pepsin in the development of laryngeal injury. Laryngoscope 1991; 101: 1-78.

20 Arianpour K, Forman SN, Karabon P, et al. Pediatric acquired subglottic stenosis: associated costs and comorbidities of 7,981 hospitalizations. Int J Pediatr Otorhinolaryngol 2019; 117: 51-56.

21 Greaney D, Russell J, Dawkins I, et al. A retrospective observational study of acquired subglottic stenosis using low-pressure, high-volume cuffed endotracheal tubes. Pediatr Anesth 2018; 28: 1136-1141.

22 Downing GJ, Kilbride HW. Evaluation of airway complications in high-risk preterm infants: application of flexible fiberoptic airway endoscopy. Pediatrics 1995; 95: 567-572.

23 Dekoninck S, Blanpain C. Stem cell dynamics, migration and plasticity during wound healing. Nat Cell Biol 2019; 21: 18-24.

24 Gurtner GC, Werner S, Barrandon Y, et al. Wound repair and regeneration. Nature 2008; 453: 314-321.

25 Golebiewska EM, Poole AW. Platelet secretion: from haemostasis to wound healing and beyond. Blood Rev 2015; 29: $153-162$.

26 desJardins-Park HE, Mascharak S, Chinta MS, et al. The spectrum of scarring in craniofacial wound repair. Front Physiol 2019; 10: 322.

27 Gleissner CA, von Hundelshausen P, Ley K. Platelet chemokines in vascular disease. Arterioscler Thromb Vasc Biol 2008; 28: 1920-1927.

28 Singer AJ, Clark RA. Cutaneous wound healing. N Engl J Med 1999; 341: 738-746.

29 Gawaz M, Vogel S. Platelets in tissue repair: control of apoptosis and interactions with regenerative cells. Blood 2013; 122: 2550-2554.

30 Kolaczkowska E, Kubes P. Neutrophil recruitment and function in health and inflammation. Nat Rev Immunol 2013; 13: 159-175.

31 Zemans RL, Briones N, Campbell M, et al. Neutrophil transmigration triggers repair of the lung epithelium via beta-catenin signaling. Proc Natl Acad Sci USA 2011; 108: 15990-15995.

32 Novak ML, Weinheimer-Haus EM, Koh TJ. Macrophage activation and skeletal muscle healing following traumatic injury. J Pathol 2014; 232: 344-355.

33 Julier Z, Park AJ, Briquez PS, et al. Promoting tissue regeneration by modulating the immune system. Acta Biomater 2017; 53: 13-28.

34 Wynn TA, Barron L. Macrophages: master regulators of inflammation and fibrosis. Semin Liver Dise 2010; 30: 245-257.

35 Quirós M, Nusrat A. Contribution of wound-associated cells and mediators in orchestrating gastrointestinal mucosal wound repair. Ann Rev Physiol 2019; 81: 189-209.

36 Lei H, Schmidt-Bleek K, Dienelt A, et al. Regulatory T cell-mediated anti-inflammatory effects promote successful tissue repair in both indirect and direct manners. Front Pharmacol 2015; 6: 184.

37 Pastar I, Stojadinovic O, Yin NC, et al. Epithelialization in wound healing: a comprehensive review. Adv Wound Care (New Rochelle) 2014; 3: 445-464.

38 Pradere JP, Kluwe J, De Minicis S, et al. Hepatic macrophages but not dendritic cells contribute to liver fibrosis by promoting the survival of activated hepatic stellate cells in mice. Hepatology 2013; 58: 1461-1473.

39 Henderson NC, Mackinnon AC, Farnworth SL, et al. Galectin-3 expression and secretion links macrophages to the promotion of renal fibrosis. Am J Pathol 2008; 172: 288-298.

40 Barrientos S, Stojadinovic O, Golinko MS, et al. Growth factors and cytokines in wound healing. Wound Repair Regen 2008; 16: 585-601.

41 Sacco O, Silvestri M, Sabatini F, et al. Epithelial cells and fibroblasts: structural repair and remodelling in the airways. Paediatr Respir Rev 2004; 5: S35-S40.

42 Clark RA. Regulation of fibroplasia in cutaneous wound repair. Am J Med Sci 1993; 306: 42-48.

43 Darby IA, Laverdet B, Bonté F, et al. Fibroblasts and myofibroblasts in wound healing. Clin Cosmet Investig Dermatol 2014; 7: 301 .

44 Coraux C, Hajj R, Lesimple P, et al. In vivo models of human airway epithelium repair and regeneration. Eur Respir Rev 2005; 14: 131.

45 Rai NK, Tripathi K, Sharma D, et al. Apoptosis: a basic physiologic process in wound healing. Int J Low Extrem Wounds 2005; 4: 138-144.

46 Greenhalgh DG. The role of apoptosis in wound healing. Int J Biochem Cell Biol 1998; 30: 1019-1030.

47 Stanton H, Melrose J, Little CB, et al. Proteoglycan degradation by the ADAMTS family of proteinases. Biochim Biophys Acta 2011; 1812: 1616-1629.

48 Hinz B. Formation and function of the myofibroblast during tissue repair. J Invest Dermatol 2007; $127: 526-537$.

49 Shah M, Foreman DM, Ferguson M. Neutralisation of TGF-beta 1 and TGF-beta 2 or exogenous addition of TGF-beta 3 to cutaneous rat wounds reduces scarring. J Cell Sci 1995; 108: 985-1002.

50 Gilbert RWD, Vickaryous MK, Viloria-Petit AM. Signalling by transforming growth factor beta isoforms in wound healing and tissue regeneration. J Dev Biol 2016; 4: 21.

51 Speight P, Kofler M, Szászi K, et al. Context-dependent switch in chemo/mechanotransduction via multilevel crosstalk among cytoskeleton-regulated MRTF and TAZ and TGF $\beta$-regulated Smad3. Nat Commun 2016; 7: 11642.

52 Singh T, Sandulache VC, Otteson TD, et al. Subglottic stenosis examined as a fibrotic response to airway injury characterized by altered mucosal fibroblast activity. Arch Otolaryngol Head Neck Surg 2010; 136: 163-170.

53 Katz R, Bastian R. Subglottic stenosis: a unique inflammatory disorder: abstract number: 1409. Arthritis Rheumatol 2015; 67: 1775-1776.

54 McAnulty RJ. Fibroblasts and myofibroblasts: their source, function and role in disease. Int J Biochem Cell Biol 2007; 39: 666-671.

55 Distler JHW, Györfi A-H, Ramanujam M, et al. Shared and distinct mechanisms of fibrosis. Nat Rev Rheumatol 2019; 15: 705-730.

56 Tampe B, Zeisberg M. Contribution of genetics and epigenetics to progression of kidney fibrosis. Nephrol Dial Transplant 2014; 29: iv72-iv79.

57 Allen RJ, Porte J, Braybrooke R, et al. Genetic variants associated with susceptibility to idiopathic pulmonary fibrosis in people of European ancestry: a genome-wide association study. Lancet Respir Med 2017; 5: 869-880. 

Ann Rheum Dis 2015; 74: 1612-1620.

59 Lucas T, Waisman A, Ranjan R, et al. Differential roles of macrophages in diverse phases of skin repair. $J$ Immunol 2010; 184: 3964-3977.

60 Hecker L, Cheng J, Thannickal VJ. Targeting NOX enzymes in pulmonary fibrosis. Cell Mol Life Sci 2012; 69: 2365-2371.

61 Kavian N, Mehlal S, Jeljeli M, et al. The Nrf2-antioxidant response element signaling pathway controls fibrosis and autoimmunity in scleroderma. Front Immunol 2018; 9: 1896.

62 Kim KK, Sheppard D, Chapman HA. TGF- $\beta 1$ signaling and tissue fibrosis. Cold Spring Harb Perspect Biol 2018; 10: a022293.

63 Singh T, Sandulache VC, Otteson TD, et al. Subglottic stenosis examined as a fibrotic response to airway injury characterized by altered mucosal fibroblast activity. Arch Otolaryngol Head Neck Surg 2010; 136: 163-170.

64 Wrana JL. Signaling by the TGF $\beta$ superfamily. Cold Spring Harb Perspect Biol 2013; 5: a011197-a.

65 Ozdamar B, Bose R, Barrios-Rodiles M, et al. Regulation of the polarity protein Par6 by TGF $\beta$ receptors controls epithelial cell plasticity. Science 2005; 307: 1603-1609.

66 Sato M, Muragaki Y, Saika S, et al. Targeted disruption of TGF- $\beta 1 /$ Smad3 signaling protects against renal tubulointerstitial fibrosis induced by unilateral ureteral obstruction. J Clin Invest 2003; 112: 1486-1494.

67 Kim K, Lu Z, Hay ED. Direct evidence for a role of $\beta$-catenin/LEF-1 signaling pathway in induction of EMT. Cell Biol Int 2002; 26: 463-476.

68 Hinz B, Lagares D. Evasion of apoptosis by myofibroblasts: a hallmark of fibrotic diseases. Nat Rev Rheumatol 2020; 16: 11-31.

69 Domino KB, Posner KL, Caplan RA, et al. Airway injury during anesthesia a closed claims analysis. Anesthesiology 1999; 91: 1703.

70 Cook TM, MacDougall-Davis SR. Complications and failure of airway management. Br J Anaesth 2012; 109: i68-i85.

71 Ono Y, Kakamu T, Kikuchi H, et al. Expert-performed endotracheal intubation-related complications in trauma patients: incidence, possible risk factors, and outcomes in the prehospital setting and emergency department. Emerg Med Int 2018; 2018: 5649476.

72 Dohar JE, Klein EC, Betsch JL, et al. Acquired subglottic stenosis-depth and not extent of the insult is key. Int $J$ Pediatr Otorhinolaryngol 1998; 46: 159-170.

73 Verwoerd-Verhoef H, Hoeve L, Bean J, et al. Management of infant laryngeal disorders in relation to wound healing processes of the rabbit larynx. Acta Otorhinolaryngol Belg 1995; 49: 313-317.

74 Jung Kwon O, Young Suh G, Pyo Chung M, et al. Tracheal stenosis depends on the extent of cartilaginous injury in experimental canine model. Exp Lung Res 2003; 29: 329-338.

75 Charous SJ, Ossoff RH, Reinisch L, et al. Canine subglottic stenosis as a model for excessive fibrosis: a pilot histologic and immunohistochemical analysis. Wound Repair Regen 1996; 4: 444-453.

Marshak G, Doyle WJ, Bluestone CD. Canine model of subglottic stenosis secondary to prolonged endotracheal intubation. Laryngoscope 1982; 92: 805-809.

Roulis M, Nikolaou C, Kotsaki E, et al. Intestinal myofibroblast-specific Tp sensing to epithelial homeostasis. Proc Natl Acad Sci USA 2014; 111: E4658.

78 Caniggia I, Tseu I, Han R, et al. Spatial and temporal differences in fibroblast behavior in fetal rat lung. Am J Physiol 1991; 261: L424-LL33.

79 Kelly NA, Murphy M, Giles S, et al. Subglottic injury: a clinically relevant animal model. Laryngoscope 2012; 122: 2574-2581.

80 Evans MJ, Winkle LSV, Fanucchi MV, et al. The attenuated fibroblast sheath of the respiratory tract epithelialmesenchymal trophic unit. Am J Respir Cell Mol Biol 1999; 21: 655-657.

81 Mota LAA, de Cavalho GB, Brito VA. Laryngeal complications by orotracheal intubation: literature review. Int Arch Otorhinolaryngol 2012; 16: 236-245.

82 Johnson LA, Rodansky ES, Sauder KL, et al. Matrix stiffness corresponding to strictured bowel induces a fibrogenic response in human colonic fibroblasts. Inflamm Bowel Dis 2013; 19: 891-903.

83 Ueha S, Shand FHW, Matsushima K. Cellular and molecular mechanisms of chronic inflammation-associated organ fibrosis. Front Immunol 2012; 3: 71.

$84 \mathrm{Li}$ Y, Jiang D, Liang J, et al. Severe lung fibrosis requires an invasive fibroblast phenotype regulated by hyaluronan and CD44. J Exp Med 2011; 208: 1459-1471.

85 Duffield JS, Forbes SJ, Constandinou CM, et al. Selective depletion of macrophages reveals distinct, opposing roles during liver injury and repair. J Clin Invest 2005; 115: 56-65.

86 Haft S, Lee JY, Ghosh A, et al. Inflammatory protein expression in human subglottic stenosis tissue mirrors that in a murine model. Ann Otol Rhinol Laryngol 2014; 123: 65-70.

87 Morrison RJ, Katsantonis N-G, Motz KM, et al. Pathologic fibroblasts in idiopathic subglottic stenosis amplify local inflammatory signals. Otolaryngol Head Neck Surg 2019; 160: 107-115.

88 Roulis M, Armaka M, Manoloukos M, et al. Intestinal epithelial cells as producers but not targets of chronic TNF suffice to cause murine Crohn-like pathology. Proc Natl Acad Sci USA 2011; 108: 5396-5401.

89 Theiss AL, Simmons JG, Jobin C, et al. Tumor necrosis factor (TNF) $\alpha$ increases collagen accumulation and proliferation in intestinal myofibroblasts via TNF receptor 2. J Biol Chem 2005; 280: 36099-36109.

90 Diaz JA, Booth AJ, Lu G, et al. Critical role for IL-6 in hypertrophy and fibrosis in chronic cardiac allograft rejection. Am J Transplant 2009; 9: 1773-1783.

91 Touat L, Fournier C, Ramon P, et al. Intubation-related tracheal ischemic lesions: incidence, risk factors, and outcome. Intensive Care Medicine 2013; 39: 575-582.

92 Wain JC. Postintubation tracheal stenosis. Semin Thorac Cardiovasc Surg 2009; 21: 284-289.

93 Módis K, Gerő D, Nagy N, et al. Cytoprotective effects of adenosine and inosine in an in vitro model of acute tubular necrosis. Br J Pharmacol 2009; 158: 1565-1578.

94 Gero D, Szabo C. Salvage of nicotinamide adenine dinucleotide plays a critical role in the bioenergetic recovery of post-hypoxic cardiomyocytes. Br J Pharmacol 2015; 172: 4817-4832. 

using cell-based screening: purine nucleosides are alternative energy sources in LLC-PK1 cells during hypoxia. Arch Biochem Biophys 2012; 517: 53-70.

96 Suzuki K, Olah G, Modis K, et al. Hydrogen sulfide replacement therapy protects the vascular endothelium in hyperglycemia by preserving mitochondrial function. Proc Natl Acad Sci 2011; 108: 13829-13834.

97 Baines CP, Kaiser RA, Purcell NH, et al. Loss of cyclophilin D reveals a critical role for mitochondrial permeability transition in cell death. Nature 2005; 434: 658-662.

98 Dhuriya YK, Sharma D. Necroptosis: a regulated inflammatory mode of cell death. J Neuroinflammation 2018; 15: 199.

99 George J, Tsuchishima M, Tsutsumi M. Molecular mechanisms in the pathogenesis of N-nitrosodimethylamine induced hepatic fibrosis. Cell Death Dis 2019; 10: 18.

100 Higgins DF, Kimura K, Bernhardt WM, et al. Hypoxia promotes fibrogenesis in vivo via HIF-1 stimulation of epithelial-to-mesenchymal transition. J Clin Invest 2007; 117: 3810-3820.

101 Philip K, Mills TW, Davies J, et al. HIF1A up-regulates the ADORA2B receptor on alternatively activated macrophages and contributes to pulmonary fibrosis. FASEB J 2017; 31: 4745-4758.

102 Taylor CT, Colgan SP. Regulation of immunity and inflammation by hypoxia in immunological niches. Nat Rev Immunol 2017; 17: 774-785.

103 Goodwin J, Choi H, Hsieh M-H, et al. Targeting hypoxia-inducible factor-1 $\alpha /$ pyruvate dehydrogenase kinase 1 axis by dichloroacetate suppresses bleomycin-induced pulmonary fibrosis. Am J Respir Cell Mol Biol 2018; 58: 216-231.

104 Copple BL, Bai S, Burgoon LD, et al. Hypoxia-inducible factor-1 $\alpha$ regulates the expression of genes in hypoxic hepatic stellate cells important for collagen deposition and angiogenesis. Liver Int 2011; 31: 230-244.

105 Roth KJ, Copple BL. Role of hypoxia-inducible factors in the development of liver fibrosis. Cell Mol Gastroenterol Hepatol 2015; 1: 589-597.

106 Manalo DJ, Rowan A, Lavoie T, et al. Transcriptional regulation of vascular endothelial cell responses to hypoxia by HIF-1. Blood 2005; 105: 659-669.

107 Distler JH, Jüngel A, Pileckyte M, et al. Hypoxia-induced increase in the production of extracellular matrix proteins in systemic sclerosis. Arthritis Rheum 2007; 56: 4203-4215.

108 Zhang Q, Wu Y, Chau CH, et al. Crosstalk of hypoxia-mediated signaling pathways in upregulating plasminogen activator inhibitor-1 expression in keloid fibroblasts. J Cell Physiol 2004; 199: 89-97.

109 Zhou G, Dada LA, Wu M, et al. Hypoxia-induced alveolar epithelial-mesenchymal transition requires mitochondrial ROS and hypoxia-inducible factor 1. Am J Physiol Lung Cell Mol Physiol 2009; 297: L1120-L1130.

110 Su Z, Li S, Zhou Z, et al. A canine model of tracheal stenosis induced by cuffed endotracheal intubation. Sci Rep 2017; 7: 45357

111 Evans D, McGlashan J, Norris A. Iatrogenic airway injury. BJA Education 2015; 15: 184-189.

112 Ganesan S, Comstock AT, Sajjan US. Barrier function of airway tract epithelium. Tissue Barriers 2013; 1: e24997-e.

113 Elosegui-Artola A, Oria R, Chen Y, et al. Mechanical regulation of a molecular clutch defines force transmission and transduction in response to matrix rigidity. Nat Cell Biol 2016; 18: 540-548.

114 Georges PC, Hui J-J, Gombos Z, et al. Increased stiffness of the rat liver precedes matrix deposition: implications for fibrosis. Am J Physiol Gastrointest Liver Physiol 2007; 293: G1147-G1154.

115 Gomez GA, McLachlan RW, Yap AS. Productive tension: force-sensing and homeostasis of cell-cell junctions. Trends Cell Biol 2011; 21: 499-505.

116 Dees C, Zerr P, Tomcik M, et al. Inhibition of Notch signaling prevents experimental fibrosis and induces regression of established fibrosis. Arthritis Rheum 2011; 63: 1396-1404.

117 Hinz B, Mastrangelo D, Iselin CE, et al. Mechanical tension controls granulation tissue contractile activity and myofibroblast differentiation. Am J Pathol 2001; 159: 1009-1020.

118 Herum KM, Choppe J, Kumar A, et al. Mechanical regulation of cardiac fibroblast profibrotic phenotypes. Mol Biol Cell 2017; 28: 1871-1882.

119 Liu F, Mih JD, Shea BS, et al. Feedback amplification of fibrosis through matrix stiffening and COX-2 suppression. J Cell Biol 2010; 190: 693-706.

120 Wipff P-J, Rifkin DB, Meister J-J, et al. Myofibroblast contraction activates latent TGF- $\beta 1$ from the extracellular matrix. J Cell Bio 2007; 179: 1311-1323.

121 Wells RG, Discher DE. Matrix elasticity, cytoskeletal tension, and TGF- $\beta$ : the insoluble and soluble meet. Sci Signal 2008; 1: pe13-pe.

122 Tobias JD. Pediatric airway anatomy may not be what we thought: implications for clinical practice and the use of cuffed endotracheal tubes. Paediatr Anaesth 2015; 25: 9-19.

123 Marston AP, White DR. Subglottic stenosis. Clin Perinatol 2018; 45: 787-804.

124 Nakarada-Kordic I, Patterson N, Wrapson J, et al. A systematic review of patient and caregiver experiences with a tracheostomy. Patient 2018; 11: 175-191.

125 Sun Y, Ge Y, Fu Y, et al. Mitomycin C induces fibroblasts apoptosis and reduces epidural fibrosis by regulating miR-200b and its targeting of RhoE. Eur J Pharmacol 2015; 765: 198-208.

126 Szabó D, Kovács D, Endrész V, et al. Antifibrotic effect of mitomycin-C on human vocal cord fibroblasts. Laryngoscope 2019; 129: E255-E262.

127 Feinstein AJ, Goel A, Raghavan G, et al. Endoscopic management of subglottic stenosis. JAMA Otolaryngol Head Neck Surg 2017; 143: 500-505.

128 Yung KC, Chang J, Courey MS. A randomized controlled trial of adjuvant mitomycin-c in endoscopic surgery for laryngotracheal stenosis. Laryngoscope 2020; 130: 706-711.

129 Smith ME, Elstad M. Mitomycin C and the endoscopic treatment of laryngotracheal stenosis: are two applications better than one? Laryngoscope 2009; 119: 272-283.

130 Rahbar R, Jones DT, Nuss RC, et al. The role of mitomycin in the prevention and treatment of scar formation in the pediatric aerodigestive tract: friend or foe? Arch Otolaryngol Head Neck Surg 2002; 128: 401-406.

131 Antón-Pacheco JL, Usategui A, Martínez I, et al. TGF- $\beta$ antagonist attenuates fibrosis but not luminal narrowing in experimental tracheal stenosis. Laryngoscope 2017; 127: 561-567. 
Simpson CB, White S, McGuff HS. Anti-transforming growth factor beta as a treatment for laryngotracheal stenosis in a canine model. The Laryngoscope 2008; 118: 546-551.

133 Voelker J, Berg PH, Sheetz M, et al. Anti-TGF- $\beta 1$ antibody therapy in patients with diabetic nephropathy. $J$ Am Soc Nephrol 2017; 28: 953-962.

134 Conte E, Fruciano M, Gili E, et al. Molecular mechanisms of pirfenidone activity in human lung fibroblasts. Eur Respir J 2014; 44 (Suppl 58): 825

135 Wollin L, Wex E, Pautsch A, et al. Mode of action of nintedanib in the treatment of idiopathic pulmonary fibrosis. Eur Respir J 2015; 45: 1434-1445. ERJ-01749-2014.

136 Milam JE, Keshamouni VG, Phan SH, et al. PPAR- $\gamma$ agonists inhibit profibrotic phenotypes in human lung fibroblasts and bleomycin-induced pulmonary fibrosis. Am J Physiol Lung Cell and Mol Physiol 2008; 294: L891-L901.

137 Celada LJ, Kropski JA, Herazo-Maya JD, et al. PD-1 up-regulation on CD4(+) T cells promotes pulmonary fibrosis through STAT3-mediated IL-17A and TGF- $\beta 1$ production. Sci Transl Med 2018; 10: eaar8356.

138 Geng Y, Liu X, Liang J, et al. PD-L1 on invasive fibroblasts drives fibrosis in a humanized model of idiopathic pulmonary fibrosis. JCI Insight 2019; 4: e125326.

139 Davis RJ, Lina I, Ding D, et al. Increased expression of PD-1 and PD-L1 in patients with laryngotracheal stenosis. Laryngoscope 2020; in press [https://doi.org/10.1002/lary.28790].

140 Duitman J, van den Ende T, Spek CA. Immune checkpoints as promising targets for the treatment of idiopathic pulmonary fibrosis? J Clin Med 2019; 8: 1547.

141 Colak S, ten Dijke P. Targeting TGF- $\beta$ signaling in cancer. Trends Cancer 2017; 3: 56-71.

142 Farah S, Doloff JC, Müller P, et al. Long-term implant fibrosis prevention in rodents and non-human primates using crystallized drug formulations. Nat Mater 2019; 18: 892

143 Love RJ, Jones KS. Biomaterials, fibrosis, and the use of drug delivery systems in future antifibrotic strategies. Crit Rev Biomed Eng 2009; 37: 259-281.

144 Bridges AW, García AJ. Anti-inflammatory polymeric coatings for implantable biomaterials and devices. $J$ Diabetes Sci Technol 2008; 2: 984-994.

145 Patil SD, Papadmitrakopoulos F, Burgess DJ. Concurrent delivery of dexamethasone and VEGF for localized inflammation control and angiogenesis. J Control Release 2007; 117: 68-79.

146 Tseng p-Y, Rele SS, Sun X-L, et al. Membrane-mimetic films containing thrombomodulin and heparin inhibit tissue factor-induced thrombin generation in a flow model. Biomaterials 2006; 27: 2637-2650.

147 Nath N, Chilkoti A. Creating "smart" surfaces using stimuli responsive polymers. Adv Mater 2002; 14: 1243-1247.

148 Duvvuri M, Motz K, Murphy M, et al. Engineering an immunomodulatory drug-eluting stent to treat laryngotracheal stenosis. Biomater Sci 2019; 7: 1863-1874.

149 Axell-House D, Yu V, Zhang Z, et al. Fibrocytes in human pulmonary fibrosis: double-blind placebo-controlled crossover pilot study of sirolimus in idiopathic pulmonary fibrosis. Chest 2017; 152: A488.

150 Namba DR, Ma G, Samad I, et al. Rapamycin inhibits human laryngotracheal stenosis-derived fibroblast proliferation, metabolism, and function in vitro. Otolaryngol Head Neck Surg 2015; 152: 881-888. 